\title{
Reenvisioning the Emergency Nurse Practitioner Role
}

An AAENP Position Statement

November 2020

(C) 2020, American Academy of Emergency Nurse Practitioners. All rights reserved. American Academy of Emergency Nurse Practitioners 7729 E. Greenway Road, \#300 Scottsdale, AZ 85260 


\section{BACKGROUND}

Despite efforts to adopt uniform employment and credentialing standards for nurse practitioners (NPs), recent evidence indicates misalignment exists with the Consensus Model for Advanced Practice Registered Nurse Regulation's (2008) recommendations (Klein et al., 2020). This impacts NPs working in emergency care settings. The Consensus Model for Advanced Practice Registered Nurse Regulation (Consensus Model) states that the scope of practice is not based on the practice setting but rather on the patient's condition and healthcare needs (APRN Consensus Workgroup, 2008). Therefore, NP scope of practice must be appropriate for the population served across settings and be understood in the context of care delivery to ensure conformity and alignment with standards for educational preparation, practice, and regulation.

Because the scope of ENP practice is not entirely encompassed within one of the currently defined six population foci, misalignments persist for the 17,000 NPs working in emergency care settings (American Association of Nurse Practitioners [AANP], 2018) and other stakeholders. As outlined in the Consensus Model, new APRN population foci may evolve.

It is the position of AAENP that the patient population served by the ENP represents a unique and significantly differentiated set of competencies from other APRN population foci. Due to the rapid evolution in emergency care delivery, and in collaboration with our national colleagues and regulatory stakeholders, AAENP supports the development of an ENP population across the lifespan.

\section{DEFINING THE POPULATION}

The NP in emergency care settings functions in a unique role to provide "care for patients across the continuum of both lifespan and acuities" (American Academy of Emergency Nurse Practitioners [AAENP], 2018a, pg. 1). While most patients are discharged following care, some patients require that the ENP "initiate complex diagnostic workups and be prepared to provide acute resuscitation and stabilization of conditions for patients requiring transfer to higher levels of care in collaboration with an interdisciplinary team" (AAENP, 2018a, pg. 4). National emergency department data (CDC, 2017), workforce statistics of NPs working in emergency care (American Academy of Nurse Practitioners Certification Board [AANPCB], 2016), and the educational model for ENPs are consistent with a new population-focus as defined by the Consensus Model.

Recognition of a new population-focus requires that educational standards and practice competencies exist, are consistent, and are nationally recognized by the profession (APRN, 2008, 
pg.13). Furthermore, this recognition is foundational to move NP curricula towards the CompetencyBased Outcome Educational standards recommended by the American Association of Colleges of Nursing (2019). AAENP, as the specialty organization representing NPs in emergency care, has established the scientific foundation for education, certification and regulation of the lifespan ENP population in the following:

- Scope and Standards of Practice - Using the Consensus Model and the ENP practice analysis as guiding frameworks, AAENP, in collaboration with ENA, updated the Scope and Standards for Emergency Nurse Practitioner Practice (AAENP, 2016).

- Certification Exam - Working with the American Academy of Nurse Practitioners Certification Board, a national practice analysis of NPs working in emergency care was performed (AANPCB, 2016). A content outline and test blueprint were developed from the findings of the practice analysis.

- Competencies for the Emergency Nurse Practitioner - Using the robust data derived from the 2016 national practice analysis, AAENP updated the original Competencies for the Emergency Nurse Practitioner (Emergency Nurses Association, 2008) to reflect the ENP's evolving role. The updated competencies (AAENP, 2018b) are nationally recognized and provide the foundation for ENP academic and fellowship curricula nationwide.

- ENP Academic and Fellowship Program Evaluation Standards - AAENP developed a voluntary review process to validate academic and fellowship program inclusion of specialty competencies and knowledge based on objective measures. The Standards for Emergency Nurse Practitioner Academic Program Validation (AAENP, 2020) strengthens and sustains the quality and integrity of ENP programs.

\section{CONSIDERATIONS IN MOVING FROM SPECIALTY TO POPULATION}

Should the specialty of emergency NP practice be redefined as a population, AAENP recognizes the potential impact of this transition in the following areas:

- Opportunities for grandfathering of currently practicing NPs in emergency care settings

- Academic curricula

- Accreditation \& Certification Programs

- Regulatory \& Credentialing Bodies

- Postgraduate Fellowship Programs

In order to continue advocating for the ENP role, AAENP anticipates continued conversations and partnerships with certifying bodies, regulatory agencies, and other stakeholders.

Regardless of the designation of the ENP as a specialty or population, AAENP will continue to promote high quality, evidence-based practice for nurse practitioners providing emergency care for patients of all ages and acuities in collaboration with an interdisciplinary team. 


\section{References}

American Academy of Emergency Nurse Practitioners. (2016). Scope and Standards for Emergency Nurse Practitioner Practice. https://www.aaenp-natl.org/assets/docs/aaenp scope and standards.pdf

American Academy of Emergency Nurse Practitioners. (2018a). Executive Summary: Current ENP Practice Data. https://www.aaenp-natl.org/assets/docs/enppractice data exec summary final.pdf

American Academy of Emergency Nurse Practitioners. (2018b). Practice standards for the emergency nurse practitioner specialty. https://www.aaenp-

natl.org/assets/docs/practice standards for the emergency nurse practitioner.pdf

American Academy of Emergency Nurse Practitioners. (2020). Standards for Emergency Nurse Practitioner Academic Program Validation. https://www.aaenp-

natl.org/assets/Standards\%20for\%20ENP\%20Academic\%20Program\%20Validation\%20\%285\%29.pdf

American Academy of Nurse Practitioners Certification Board. (2016). Executive summary of the 2016 practice analysis of emergency nurse practitioners.

https://www.aanpcert.org/resource/documents/AANPCB\%202016\%20ENP\%20Practice\%20Analysis\% 20Executive\%20Summary.pdf

American Association of Colleges of Nursing. (2019). AACN's vision for academic nursing: Executive summary. https://www.aacnnursing.org/Portals/42/News/White-Papers/Vision-Academic-Nursing.pdf

American Association of Nurse Practitioners. (2018). Number of nurse practitioners hits new record high. https://www.aanp.org/press-room/press-releases/173-press-room/2018-press-releases/2190-numberof-nurse-practitioners-hits-new-record-high

APRN Consensus Work Group \& the National Council of State Boards of Nursing APRN Advisory Committee. (2008). Consensus model for APRN regulation: Licensure, accreditation, certification, \& education. https://www.ncsbn.org/Consensus Model for APRN Regulation July 2008.pdf

Centers for Disease Control (2017). National hospital ambulatory medical care survey: 2017 emergency department summary tables. https://www.cdc.gov/nchs/data/nhamcs/web tables/2017 ed web tables508.pdf

Emergency Nurses Association. (2008). Competencies for nurse practitioners in emergency care. https://cdn.ymaws.com/www.nonpf.org/resource/resmgr/competencies/compsfornpsinemergencycarefi nal.pdf

Klein, Ta., Kaplan, L., Stanik-Hutt, J., \& Cote, J. (2020). Hiring \& credentialing of nurse practitioners as hospitalists: a national workforce analysis. Journal of Nursing Regulation, 11(3), 33-43. 